\title{
Correction to: New numerical approximation of fractional derivative with non-local and non-singular kernel: application to chaotic models
}

\author{
Mekkaoui Toufik ${ }^{1, a}$, Abdon Atangana ${ }^{2, b}$ \\ ${ }^{1}$ Department of Applied Mathematics, Faculty of Science, Université Moulay Ismail, B.P. 11201, Zitoune Meknès, Morocco \\ 2 Institute for Groundwater Studied, Faculty of Natural and Agricultural Science, University of Free State, 9300 Bloemfontein, South Africa \\ (C) The Author(s), under exclusive licence to Società Italiana di Fisica and Springer-Verlag GmbH Germany, part of Springer Nature 2022
}

\section{Correction to: Eur. Phys. J. Plus (2017) 132:444}

https://doi.org/10.1140/epjp/i2017-11717-0

In this article, Eq. 14 has been corrected. It was published as:

$$
\sum_{k=0}^{n}(n-k+2+\alpha)=\frac{n(n+4+2 \alpha)}{2}
$$

It has been changed to:

$$
\sum_{k=0}^{n}(n-k+2+\alpha)=\frac{(n+1)(n+4+2 \alpha)}{2}
$$

In the next equation evaluating the error, the above sum is replaced. This does not affect the formulation of the numerical scheme or the rest of the paper.

The original article has been corrected.

The original article can be found online at https://doi.org/10.1140/epjp/i2017-11717-0.

a e-mail: toufik_mekkaoui@yahoo.fr

b e-mail: AtanganaA@ufs.ac.za (corresponding author) 